\title{
EFFECT OF PHENTOLAMINE MESYLATE ON THE INCIDENCE OF SELF-INFLICTED SOFT TISSUE INJURY FOLLOWING INFERIOR ALVEOLAR NERVE BLOCK ANESTHESIA IN CHILDREN: (RANDOMIZED CONTROLLED CLINICAL TRIAL)
}

\author{
Emmanuella R. Beshara ${ }^{1} B D S$, Aly A. Sharaf ${ }^{2} P h D$, Nadia A. Wahba ${ }^{3} P h D$
}

\begin{abstract}
INTRODUCTION: One of the shortcomings of local anesthesia (LA) is that the soft tissue anesthesia (STA) typically lasts for 3 to 5 hours while most routine dental procedures are completed in less than an hour. Pediatric patients particularly may accidently bite on their lips.

OBJECTIVES: The study was conducted to evaluate the effectiveness of phentolamine mesylate (PM) on the reduction of the incidence of selfinflicted soft tissue injury (STI) and its effect on the time of return of normal function, after inferior alveolar nerve block anesthesia.

MATERIALS AND METHODS: The study is a blinded randomized controlled parallel group clinical trial with a 1:1 allocation ratio. A total of eighty pediatric patients, with an age range of 5-8 years, selected from the Pediatric Dentistry out-patient clinic, Faculty of Dentistry, Alexandria University, after obtaining necessary consents. Inferior alveolar nerve block anesthesia (2 percent lidocaine with 1:100,000 epinephrine) was administered in the recommended dose. After completion of the operative procedure, participants were randomly allocated into 2 groups: study and control group. The experimental group received a PM injection using the same technique employed for administration of LA, in a cartridge ratio of 1:1. The control group did not receive any reversal agent. The incidence of self-inflicted STA and return to normal function were recorded post-operatively and STI was followed up after 24 hours.

RESULTS: There were no significant differences in the incidence of self-inflicted STI between the PM and control group except for the occurrence of ulcers after 24 hours $(\mathrm{P}=0.04)$. Phentolamine mesylate accelerated the median time of return to normal function $(\mathrm{P}=0.001)$.

CONCLUSION: Phentolamine mesylate was efficacious in reducing the incidence of self-inflicted soft-tissue ulceration and accelerated the time of return to normal function after LA.

KEYWORDS: Local anesthesia; Phentolamine mesylate; Soft tissue ulcer.
\end{abstract}

1. Bachelor of Dentistry, Faculty of Dentistry, Alexandria University, Alexandria, Egypt.

2. Professor of Pediatric Dentistry, Department of Pediatric Dentistry and Dental Public Health, Faculty of Dentistry, Alexandria University, Alexandria, Egypt.

3. Professor of Pediatric Dentistry, Department of Pediatric Dentistry and Dental Public Health, Faculty of Dentistry, Alexandria University, Alexandria, Egypt.

*Corresponding author emmanuella_rizk@hotmail.com

\section{INTRODUCTION}

Local anesthetics are the most widely used drugs in dentistry for the management of pain (1). Vasoconstrictors are added to oppose the unwanted vasodilatory effect of the local anesthetics, however, its addition greatly prolongs the duration of the soft tissue anesthesia (STA) (2).

Most dental procedures are of relatively short duration, lasting, on an average of 44 minutes $(3,4)$. Residual STA of the supporting tissues remain for several hours after pulpal anesthesia has been lost. Although this might be favorable after surgical interventions, but most dental treatments do not require pain management once the patient is discharged (2). A survey of 250 adult dental patients revealed that $88 \%$ were interested in an option that reverses this numbness, even if it required an additional injection and added to the cost of the dental procedure (5).

The most detrimental consequence of the STA is the perpetual effect, which can lead to self-inflicted soft tissue injury (STI) of the lips, tongue and/or cheeks $(6,7)$. College et al., (2000), reported trauma frequency as $18 \%, 16 \%, 13 \%$ 
and 7\% in children who are; less than 4, 4-7, 8-11 and more than 12 years old, respectively (6). Traumatic STI can occur in any patient but it is in the pediatric and mentally disabled patients where it is more prone to occur $(8,9)$. To avoid this undue harm, it would be better to reverse the effects of LA once the required treatment has been completed.

The search for a pharmacologic means of minimizing postoperative anesthesia has focused on phentolamine mesylate (PM), where an injectable form has been developed (10). Phentolamine mesylate has been used in the treatment and diagnosis of several medical conditions since 1952 (11-13). Phentolamine mesylate acts as a competitive inhibitor to epinephrine and blocks its effect by blocking $\alpha$-adrenergic receptors causing smooth muscle relaxation. The introduction of PM causes vasodilation at the site where the anesthetic agent was injected; this leads to higher absorption of local anesthetic and thus reduces the duration of anesthesia (14).

A specific preparation of PM for the reversal of softtissue anesthesia was approved by the FDA in May 2008, to be used for patients older than 6 years of age and weighing more than $15 \mathrm{~kg}$. Later, in March 2016, the FDA approved its use in pediatric patients 3 years and older. Dosage form of OraVerse (phentolamine mesylate) is $0.4 \mathrm{mg} / 1.7 \mathrm{ml}$ solution per cartridge. It is administered in an equal volume to the LA, up to a maximum of 2 cartridges in adults. OraVerse is administered at the same location and by the same technique used previously for the LA $(15,16)$.

In spite of PM's safety (17), few studies in the literature were performed to evaluate the effect of PM on the associated self-inflicted STI resulting from injection of LA. This triggered the need to study the incidence of selfinflicted STI after using PM to reverse the residual STA. The null hypothesis was that there is no difference in incidence of self- inflicted STI in patients receiving PM and those who do not receive the reversal agent.

\section{MATERIALS AND METHODS}

The study is a blinded randomized controlled parallel group clinical trial, with a 1:1 allocation ratio (PM: control). It was set up and reported according to the CONSORT guidelines (18). The research protocol was approved by the Ethical Committee of the Faculty of Dentistry, Alexandria University, and an informed consent was obtained from each patient after providing detailed information and description of the study. The study took place at the outpatient clinic of Pediatric Dentistry and Dental Public Health Department, Faculty of Dentistry, Alexandria University, Egypt.

The minimal sample size was calculated based on a previous study by Tavares et al (2008) (19). By using a statistical tool to calculate the mean from median values (20), the data resulted in large effect size $(d=0.70)$, which when adopted resulted in a minimum required sample size per group of 34 patients (number of groups $=2$ ). Thus, total sample size needed $=68$ patients was the enough required sample to detect a standardized effect size of 0.70 of the outcome $(21,22)$, as statistically significant with $80 \%$ power and at a significance level of 95\% (alpha error accepted = $0.05)$. Sample size per group will be increased to 40 (17.5\%) to control for withdrawal (attrition) bias (23). The sample size was calculated using IBM SPSS Sample Power software 3.0.1 (24).

This study was conducted on 80 pediatric patients, with an age range of 5-8 years, attending the outpatient clinic of the of Pediatric Dentistry and Dental Public Health Department, Faculty of Dentistry, Alexandria University, for routine dental procedures.

\section{Eligibility criteria}

The participants enrolled in this study were selected after fulfilling the following criteria:

- Patients in need of restorative dental procedures, requiring inferior alveolar nerve block anesthesia.

- An age range of 5-8 years.

- Healthy children (physical status ASA I) (25).

- Definitely positive or positive patients on Frankl scale (26).

- Normal lip sensation before administration of LA.

- Normal pediatric functional assessment battery (pFAB); reported normal for smiling, speaking and drinking, and absent for drooling (16).

\section{Exclusion criteria}

- Patients requiring surgical procedures (i.e. extractions).

- Patients who were not trainable in the standardized lip tapping procedure (could not learn to distinct the anesthetized numb side from the non-anesthetized side).

- Patients who did not achieve profound numbness, requiring additional anesthesia.

Randomization and Allocation concealment

The children were randomly allocated after fulfilling inclusion criteria, using computer based random allocation technique (27). The list of allocation was generated prospectively using the random allocation software where participants were allocated in blocks of four. The allocation was sealed in sequentially numbered opaque envelopes by an assistant and the set of envelopes was given to the supervisor. When enrolling a new participant for the intervention, the supervisor supplied the designated envelope, on which the name was recorded and allocation retrieved.

The participants and the statistician were blinded to the treatment groups. The operator, who was also the examiner, was not blinded to the treatment as the test group received a PM injection while the control group did not receive a reversal agent.

All participants were randomly divided into two groups Group I: Study group (PM), (n) =40: In which forty patients received local anesthesia followed by a phentolamine mesylate (PM) injection after completion of the operative procedure.

Group II: Control group, $(n)=40$ : In which forty patients received local anesthesia and did not receive any reversal agent after completion of the operative procedure. 


\section{Methods and Assessments}

Prior to initiation of the study, the operator/investigator was trained to assess lip numbness using index finger palpation and tapping with comparison to the non-anesthetized side, and to evaluate functional deficits by using the pFAB, in 10 patients not involved in the study.

For all subjects: the demographic data were collected, medical and dental history obtained, dental examination performed. Patients' weights were recorded and an informed consent was obtained.

\section{1)Local anesthetic administration}

All patients received topical anesthetic gel [Benzocaine 0.2 mL 20\% (Alpha-Caine ${ }^{\mathrm{TM}}$, DENTAL TECHNOLOGIES, INC. U.S.A)], after which they received LA [Lidocaine $2 \%$ with Epinephrine 1:100,000 (Octacaine 100 Local anesthetic, Novocol Pharmaceutical, Canada Inc.)], utilizing a standard inferior alveolar nerve (involves the insertion of the needle near the mandibular foramen in order to deposit local anesthetic near to the inferior alveolar nerve before it enters the foramen) (2). Patients who weighed greater than $15 \mathrm{~kg}$ and less than $30 \mathrm{~kg}$ were given only half the anesthetic cartridge, while patients who weighed 30 kilograms or more were given one full anesthetic cartridge (16). Instructions were given to the children not to bite on their lips.

\section{2)Lip tapping training}

Five minutes after administration of LA, effective anesthesia of the soft tissues was confirmed using a standardized procedure; that involves light tapping of the lip with the operator's index finger. The patient's response of “yes" or "no" was recorded as indicative of feeling or not feeling the stimulus. They were instructed that this procedure will be repeated and that every time they should report either feeling normal or numb on the anesthetized side, in comparison to the non-anesthetized side (19).

Children who had not achieved profound lip numbness, requiring additional anesthesia, or those who could not learn to distinct the numb anesthetized side from the non-anesthetized side, were excluded from the study (28), but were still offered the intended dental procedure in the same visit.

\section{3) Operative procedure}

The operative procedure was performed within 30 minutes or less from the time of administration of LA. Procedures included pulpotomies, stainless steel crowns and fillings in primary and permanent teeth.

4)The pediatric Functional Assessment Battery (pFAB) (16)

After completion of the dental procedure, pFAB was performed. Children were asked to give a big smile, pronounce 10 words, drink water (3oz), and the presence of drooling was noted (29, 30). These functional assessments were rated as normal or abnormal. The return to normal function was considered to occur when all functional tests were rated as normal for the patient's last pFAB and one or more of these functions were rated as not normal in the previous assessment.
After the operative procedure was completed, the operator was supplied with the designated envelope, where the name of the participant was recorded on the envelope and then the envelope was opened and the allocation retrieved (31).

\section{5) Phentolamine Mesylate administration}

For group I (study group): Patients received the reversal agent Phentolamine Mesylate injection [( $0.4 \mathrm{mg} / 1.7 \mathrm{~mL}$ solution per cartridge) supplied in a dental cartridge. (Oraverse $^{\mathrm{TM}}$, Novocol Pharmaceutical, Canada, Inc. for Septodont, Inc.)], which was administered at a cartridge ratio of $1: 1$ to LA (1 cartridge for children over $30 \mathrm{~kg}, 1 / 2$ cartridge for children $15-30 \mathrm{~kg}$ ) (32). This was done using the same location and technique employed for the administration of the LA.

For group II (control group): No reversal agent or any other injections was given after completion of the operative procedure.

\section{6) Observation period}

The same operator examined all patients during the observational period for:

(1)Self-inflicted STI; was recorded two times for each patient; at the time of dismissal and after 24 hours, to reveal the time at which the injury, if any, had occurred. STI was documented in the form of redness, hematoma, swelling or ulcer, each recorded separately.

(2) Time to normal function as measured and recorded by (pFAB).

For study group (group I): After 10 minutes from the PM injection: (a) lip tapping test was performed and repeated every ten minute, until the patient reported feeling both sides equally normal and self-inflicted STI was recorded at the time of dismissal, (b) time to normal function was measured by $\mathrm{pFAB}$, every 15 minutes and for the following two hours.

For control group (group II): After 10 minutes from completion of the operative procedure the previous tests employed for group I were performed, but without administration of the reversal agent.

\section{7) Follow up}

A recall visit, after 24 hours, was scheduled to assess selfinflicted STI in the form of redness, hematoma, swelling or ulcer, each recorded separately.

\section{Statistical analysis}

Chi square test was used to compare the study groups regarding the occurrence of redness, swelling, ulcer and hematoma at the time of dismissal and at the 24 hour follow up visit. Whereas, within groups differences were assessed by McNemar's test. Kaplan-Meier analysis was applied to measure the fraction of patients regaining normal FAB for a certain amount of time. The data was analyzed using IBM SPSS Statistics for windows, version 25.0. Armonk, NY: IBM Corp.

\section{RESULTS}

Among 110 children screened for participation, 80 were randomized to study or control group in a $1: 1$ ratio; 17 children were not randomized because they failed to meet 
eligibility criteria, one child refused to participate. After LA administration; 9 children were not randomized because they could not be trained during lip tapping procedure (could not distinct the numb anesthetized side from the non-anesthetized side). Additionally, 3 children did not achieve profound lip numbness, requiring additional anesthesia and were excluded prior to randomization. The remaining 80 participants completed the study. Participants were recruited from March 2018 to December 2018. (Figure 1)

The study group comprised 20 boys and 20 girls, with a mean age of $6.60 \pm 1.15$ and a mean weight of $23.87 \pm 5.39$. The control group comprised 28 boys and 12 girls, with a mean age of $6.38 \pm 1.27$ and a mean weight of $25.20 \pm 6.54$. Age, gender and weight were not significantly different between the two groups, $(\mathrm{P}=0.41, \mathrm{P}=0.07, \mathrm{P}=0.32)$ respectively.

\section{A. Incidence of self-inflicted soft tissue injury (STI) (Table} 1)

1. Table (1) showed a comparison between the occurrence of redness, swelling, ulcer and/or hematoma, at the time of dismissal and at the 24 hour follow up visit.

a. In the study group; there was an insignificant difference between the occurrence of redness $(\mathrm{P}=0.50)$, ulcer $(\mathrm{P}=1.00)$, swelling $(\mathrm{P}=1.00)$ or hematoma $(\mathrm{P}=1.00)$, at the time of dismissal of the patients and at the 24 hour follow up visit.

b. In the control group; there was a statistically significant difference between the occurrence of redness $(\mathrm{P}=0.008)$, ulcer $(\mathrm{P}=0.03)$ and swelling $(0.01)$ at the time of dismissal and at the 24 hour follow up visit, but there was an insignificant difference between the occurrence of hematoma $(\mathrm{P}=1.00)$ at the time of dismissal and at the 24 hour follow up visit.

2. Table (1) showed a comparison between the two groups with regards to the occurrence of redness, swelling, ulcer and hematoma.

a. At the time of dismissal: there was an insignificant difference in the occurrence of redness $(\mathrm{P}=0.26)$, ulcer $(\mathrm{P}=0.72)$, swelling $(\mathrm{P}=0.74)$ or hematoma $(\mathrm{P}=0.55)$.

b. At the 24 hour follow up visit: more ulcers were recorded in the control group, where the statistical difference was $(\mathrm{P}=0.04)$. No statistically significant difference was analyzed in the occurrence of redness $(\mathrm{P}=0.13)$, swelling $(\mathrm{P}=0.18)$ or hematoma $(\mathrm{P}=0.30)$.

3. Upon comparing the two groups; with regards to the occurrence of redness, swelling, ulcer and hematoma, throughout the whole study time, it was shown that; There was no significant difference in the occurrence of any of the following; redness $(\mathrm{P}=0.32)$, ulcer $(\mathrm{P}=0.09)$, swelling $(\mathrm{P}=0.18)$ or hematoma $(\mathrm{P}=0.30)$, between both groups, when time factor was not put into consideration (Table 2).

B. Time to return of normal function as measured by the Functional Assessment Battery (pFAB) (Table 3)

In the study group; the median time to normal function was 30 minutes (95\% confidence interval: 22.25 to 37.74 minutes), while in the control group; the median time to normal function was 60 minutes (95\% confidence interval: 51.93 to 68.06 minutes).

At the end of the two-hour observation period; 3 patients $(7.5 \%)$ in the experimental group and 7 patients (17.5\%) in the control group had not recovered to normal function. The log-rank test of the time to return of normal function in $\mathrm{pFAB}$ was statistically significant $(\mathrm{P}=0.001)$. The Kaplan-Meier plot of the time to return of normal function in pFAB is displayed in (Figure 2).

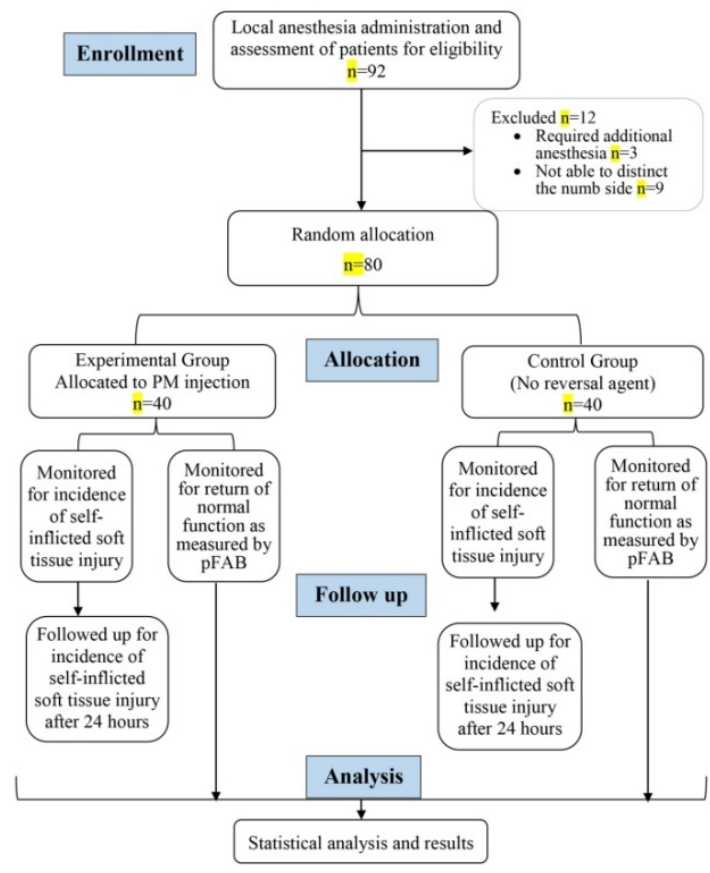

Figure (1): Flow chart of the study design.

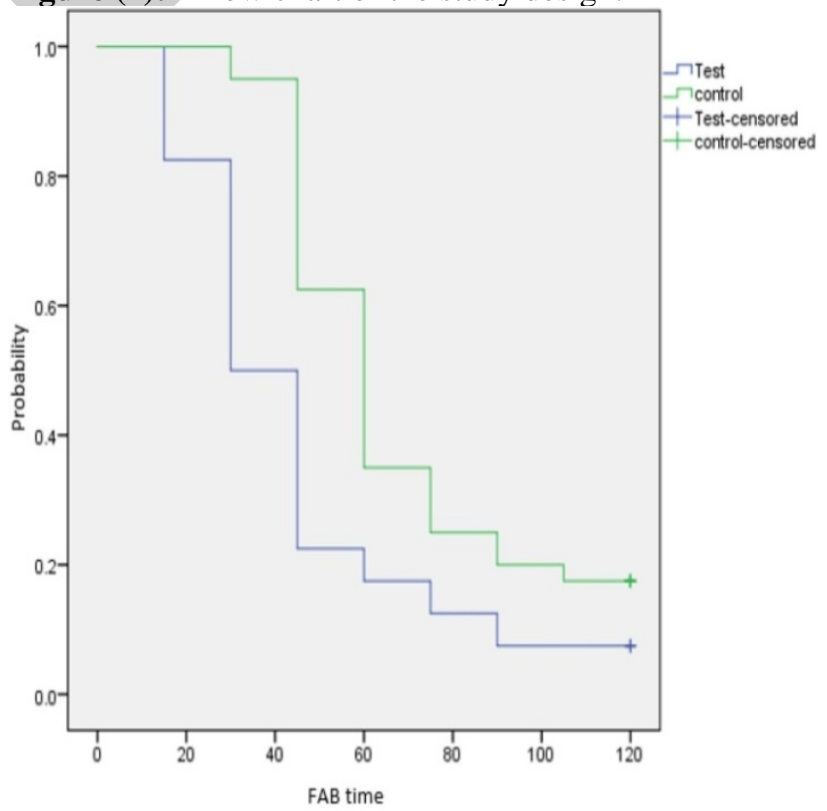

Figure (2): Kaplan-Meier Plot, time to return of normal function in pFAB. 
Table (1):Incidence of self-inflicted soft tissue injury at the time of dismissal and at the 24 hour follow-up visit.

\begin{tabular}{|c|c|c|c|c|c|}
\hline \multicolumn{3}{|l|}{ Variables } & $\begin{array}{l}\text { Group I } \\
(n=40)\end{array}$ & $\begin{array}{l}\text { Group II } \\
(n=40)\end{array}$ & $\begin{array}{l}p \\
\text { value }\end{array}$ \\
\hline \multirow{4}{*}{ Redness } & \multirow{2}{*}{$\begin{array}{l}\text { At } \\
\text { dismissal }\end{array}$} & Yes & $10(25 \%)$ & $6(15 \%)$ & \multirow{2}{*}{0.26} \\
\hline & & No & $30(75 \%)$ & $34(85 \%)$ & \\
\hline & \multirow{2}{*}{$\begin{array}{ll}\text { After } & 24 \\
\text { hours } & \\
\end{array}$} & Yes & $8(20 \%)$ & $14(35 \%)$ & \multirow{2}{*}{0.13} \\
\hline & & No & $32(80 \%)$ & $26(65 \%)$ & \\
\hline \multicolumn{3}{|l|}{ P value } & 0.50 & $0.008 *$ & \\
\hline \multirow{4}{*}{ Ulcers } & \multirow{2}{*}{$\begin{array}{l}\text { At } \\
\text { dismissal }\end{array}$} & Yes & 4 (10\%) & $\begin{array}{l}5 \\
(12.5 \%)\end{array}$ & \multirow[t]{2}{*}{0.72} \\
\hline & & No & $36(90 \%)$ & $35(87 \%)$ & \\
\hline & \multirow{2}{*}{$\begin{array}{l}\text { After } 24 \\
\text { hours }\end{array}$} & Yes & $4(10 \%)$ & $\begin{array}{l}11 \\
(27.5 \%)\end{array}$ & \multirow{2}{*}{$0.04 *$} \\
\hline & & No & 36 (90\%) & $\begin{array}{l}29 \\
(72.5 \%)\end{array}$ & \\
\hline \multicolumn{3}{|l|}{$P$ value } & 1.00 & $0.03 *$ & \\
\hline \multirow{4}{*}{ Swelling } & \multirow{2}{*}{$\begin{array}{l}\text { At } \\
\text { dismissal }\end{array}$} & Yes & 6 (15\%) & $\begin{array}{l}5 \\
(12.5 \%)\end{array}$ & \multirow{2}{*}{0.74} \\
\hline & & No & 34 (85\%) & $\begin{array}{l}35 \\
(87.5 \%)\end{array}$ & \\
\hline & \multirow{2}{*}{$\begin{array}{l}\text { After } 24 \\
\text { hours }\end{array}$} & Yes & $\begin{array}{l}7 \\
(17.5 \%)\end{array}$ & $12(30 \%)$ & \multirow{2}{*}{0.18} \\
\hline & & No & $\begin{array}{l}33 \\
(82.5 \%)\end{array}$ & 28 (70\%) & \\
\hline \multicolumn{3}{|l|}{ P value } & 1.00 & $0.01^{*}$ & \multirow{3}{*}{0.55} \\
\hline \multirow{4}{*}{ Hematoma } & \multirow{2}{*}{$\begin{array}{l}\text { At } \\
\text { dismissal }\end{array}$} & Yes & $2(5 \%)$ & $1(2.5 \%)$ & \\
\hline & & No & 38 (95\%) & $\begin{array}{l}39 \\
(97.5 \%)\end{array}$ & \\
\hline & \multirow[b]{2}{*}{$\begin{array}{l}\text { After } 24 \\
\text { hours }\end{array}$} & Yes & $3(7.5 \%)$ & $1(2.5 \%)$ & \multirow{2}{*}{0.30} \\
\hline & & No & 37 (92\%) & $\begin{array}{l}39 \\
(97.5 \%)\end{array}$ & \\
\hline \multicolumn{3}{|l|}{ P value } & 1.00 & 1.00 & \\
\hline
\end{tabular}

*Statistically significant at $\mathrm{p}$ value $\leq 0.05$

Table (2):Distribution of study participants according to soft tissues injuries.

\begin{tabular}{|c|c|c|c|c|}
\hline \multirow{2}{*}{\multicolumn{2}{|c|}{ Variables }} & $\begin{array}{l}\text { Group I } \\
(n=40)\end{array}$ & $\begin{array}{l}\text { Group II } \\
(n=40)\end{array}$ & \multirow[t]{2}{*}{ p value } \\
\hline & & n (\%) & & \\
\hline \multirow{2}{*}{ Redness } & yes & $10(25 \%)$ & 14 (35\%) & \multirow{2}{*}{0.32} \\
\hline & no & 30 (75\%) & $26(65 \%)$ & \\
\hline \multirow{2}{*}{ Ulcers } & yes & 5 (12.5\%) & 11 (27.5\%) & \multirow{2}{*}{0.09} \\
\hline & no & 35 (87.5\%) & 29 (72.5\%) & \\
\hline \multirow{2}{*}{ Swelling } & yes & 7 (17.5\%) & $12(30 \%)$ & \multirow{2}{*}{0.18} \\
\hline & no & 33 (82.5\%) & 28 (70\%) & \\
\hline \multirow{2}{*}{ Hematoma } & yes & $3(7.5 \%)$ & $1(2.5 \%)$ & \multirow{2}{*}{0.30} \\
\hline & no & 37 (92\%) & 39 (97.5\%) & \\
\hline
\end{tabular}

Table (3): Time to return of normal function in pFAB.

\begin{tabular}{|c|c|c|}
\hline \multirow{2}{*}{$\begin{array}{l}\text { Time to return of } \\
\text { normal function in } \\
\text { pFAB }\end{array}$} & $\begin{array}{l}\text { Group I } \\
(n=40)\end{array}$ & $\begin{array}{l}\text { Group II } \\
(n=40)\end{array}$ \\
\hline & \multicolumn{2}{|l|}{ n (\%) } \\
\hline $\begin{array}{l}1-15 \text { min after } \\
\text { procedure }\end{array}$ & $7(17.5 \%)$ & $0(0 \%)$ \\
\hline $\begin{array}{l}16-30 \quad \min \text { after } \\
\text { procedure }\end{array}$ & $13(32.5 \%)$ & $2(5 \%)$ \\
\hline $\begin{array}{l}31-45 \text { min after } \\
\text { procedure }\end{array}$ & $11(27.5 \%)$ & 13 (32.5\%) \\
\hline $\begin{array}{l}46-60 \text { min after } \\
\text { procedure }\end{array}$ & $2(5 \%)$ & $11(27.5 \%)$ \\
\hline $\begin{array}{l}61-75 \text { min after } \\
\text { procedure }\end{array}$ & $2(5 \%)$ & $4(10 \%)$ \\
\hline $\begin{array}{l}76-90 \quad \min \text { after } \\
\text { procedure }\end{array}$ & $2(5 \%)$ & $2(5 \%)$ \\
\hline $\begin{array}{l}91-105 \text { min after } \\
\text { procedure }\end{array}$ & $0(0 \%)$ & $1(2.5 \%)$ \\
\hline $\begin{array}{l}106-120 \text { min after } \\
\text { procedure }\end{array}$ & $0(0 \%)$ & $0(0 \%)$ \\
\hline $\begin{array}{l}\text { Not recover normal } \\
\text { function at the end } \\
\text { of the } 2 \text {-hour } \\
\text { observation period }\end{array}$ & $3(7.5 \%)$ & $7(17.5 \%)$ \\
\hline $\begin{array}{l}\text { Median time to } \\
\text { normal function in } \\
\text { min }(95 \% \mathrm{CI})\end{array}$ & $30(22.25,37.74)$ & $\begin{array}{l}60 \\
68.06)\end{array}$ \\
\hline $\begin{array}{l}\text { p-value for log-rank } \\
\text { test }\end{array}$ & $0.001 *$ & \\
\hline
\end{tabular}

*Statistically significant at p value $\leq 0.05$

$\uparrow \mathrm{pFAB}=$ pediatric Functional Assessment Battery.

\section{DISCUSSION}

There have been theories suggesting a possible link between the reversal of STA and a decrease in self-inflicted STI. However, the manufacturer does not claim the agent reduces STI and available published studies evaluating the effect of PM on self-inflicted STI are extremely limited $(33,28)$.

The results of present study indicate that PM can reduce post-operative self-inflicted soft tissue ulcers, which seemed to occur more often in the control group who were dismissed with residual STA, unlike the PM group. Phentolamine mesylate did not significantly reduce other milder forms of STI as redness, swelling and hematoma. In fact more patients in the PM group reported hematoma at the injection site. In regards to return to normal function, a statistically and clinically significant acceleration in the time of return to normal function was demonstrated for the PM group compared to the control group.

The proposed mechanism of action of PM, an antagonist to vasoconstrictor, with regard to LA reversal is that; it increases local blood flow resulting in the clearance of LA from the sub-mucosal tissues to the circulation (19). 
Since lidocaine with 1:100,000 epinephrine is largely the most frequently used dental LA; it was the LA of choice in our study (34).

In the current study, children who required surgical procedures were excluded, because in this case postoperative STA maybe favorable to avoid post-procedural pain. During the lip tapping training children were instructed to report either feeling normal or numb on the anesthetized side, in comparison to the non-anesthetized side. Patients who showed uncooperative behavior and could not be trained to assess the numbness of their lower lip during the lip tapping training were excluded. An age range of five to eight was selected to establish a homogeneous group in order to reduce variability of response, especially that our trial involved dosages; the amount of LA sufficient to produce effective numbness would greatly vary between considerably different age groups. To understand the protocol of lip tapping training, patients were required to have a certain intellectual level which may not be the case in patients younger than 5 years. Therefore, randomization was done after LA administration to ensure cooperative and cognitive ability of the child. Likewise, children who had not achieved profound lip numbness (who responded "no" to numbness) requiring additional anesthesia, were excluded from the study to avoid exceeding the maximum dose recommended by the manufacturer for the usage of PM in children, which must be administered in a $1: 1$ ratio to $L A$.

In the present study, patients did not receive a sham/placebo injection because the FDA later indicated that this is an unnecessary risk to the child (16). Additionally, patients were instructed not to bite on their lips after LA administration for ethical considerations.

Our results showed a significant reduction in the occurrence of self-inflicted ulcers, among patients in the PM group compared to patients in the control group when examined the next day during a recall visit. Although, at the time of dismissal of the patients, such significant difference in the occurrence of ulcers was not noted among the two groups. Namely, self-inflicted soft tissue ulcers were more likely to be reported in the control patients who were not administered PM. Other forms of self-inflicted STI, such as redness and swelling, were insignificantly reduced, unlike ulcers, for patients in the PM group when compared to those patients in the control group. In fact, hematoma was encountered more at the injection site in patients in PM group when compared to the control group, predictively because of the second injection.

Upon comparing STI within each group at the time of dismissal and on the next day; the PM group showed no significant difference in the occurrence of any of the forms of STI (redness, ulcer, swelling or hematoma) between the two times of examination, while in the control group the rates of occurrence of redness, ulcers and swelling were significantly increased on the next day during the follow up visit when compared to their occurrence at the time of dismissal.
These outcomes may be explained by the extended STA time induced by the LA (3-5 hours) and a relatively lesser observation period (two hours post-procedural), after which the control patients were discharged. In another words, most of the patients in the control group were dismissed while still numb and ulcerations had occurred after dismissal and documented on the next day, unlike the patients in the PM group whom residual STA was hastened due to the administration of PM and were all dismissed with no residual numbness and therefore self-mutilation was unlikely to occur (33).

College et al., (2000) published the first study to document post-anesthetic STI prevalence in a pediatric population. It was found that; by age group, trauma frequency was $18 \%$ (< 4 yrs.), 16\% (4-7 yrs.), 13\% (8-11 yrs.) and $7 \%$ (> 12 yrs.) (6).

In the present study, although not statistically significant, the overall incidence of self-inflicted STI (in the form of redness, ulcer, swelling and hematoma) for the PM group was lower than that with patients in the control group who were not administered PM. This comes in agreement with a study conducted by Boynes et al., 2013, which reported reduced occurrence of self-inflicted STI after administration of PM (33). Boynes et al., 2013 examined various complications resulting from injecting dental local anesthetic with and without administration of PM and stated that generally, of all the complications examined, selfinflicted soft tissue injury was the most frequently encountered complication and reported a reduction in the complications with the administration of PM, particularly as it relates to self-inflicted STI (33).

In assessing our secondary outcome; pFAB was used to evaluate oral functional deficiencies caused by the prolonged STA. The pFAB included evaluation of smiling, speaking, drinking and the presence or absence of drooling. The researcher rated each of these functional assessments as normal or abnormal. The pFAB test was developed by Novalar Pharmaceuticals for this specific purpose and had been formerly used in a few studies $(16,34)$.

Results showed that PM reduced the median recovery time to normal function; 30 minutes for PM-treated patients compared to 60 minutes in the control group patients. Recovery of patients' functions were quicker for patients in the PM group than for those in the control group $(\mathrm{P}=0.001)$.

A study conducted by Hersh et al., (2008) on adolescents and adults, also reported a statistically significant difference in the recovery of normal function between both groups $(\mathrm{P}<.0001)$. The median time to normal function in FAB was 60 minutes for the PM group versus 120 minutes in the control group. The difference in the reported time of return to normal function, maybe related to the older age of the population studied by Hersh et al., (2008), (12 to 92 years) in this study, permitting more LA cartridges to be administered than that usually used in our pediatric population (34). In a more recent study conducted by Hersh 
et al., (2017), on pediatric patients less than six years old, the median time of recovery of normal function was 31 minutes in the PM group and 45 minutes in the control group, as measured by the pFAB. Unlike our analysis, this difference was not statistically significant $(\mathrm{P}=0.0559)(16)$.

An unanticipated trend was shown where; the recovery of normal function occurred more rapidly than did subjective assessments of numbness i.e. function returned to normal in the presence of numbness (abnormal sensation). This comes in agreement with Hersh et al., (2008), who reported a similar tendency of function recovering before lip numbness dissipation (34). Although the pFAB testing was successfully utilized previously and in our study; the motor function of the lip evaluated by "smiling" seemed slightly affected in some patients, even with definite lip numbness. In future studies perhaps other ways of assessing oral function would be more objective and reliable in which the objectivity of this pFAB test could be enhanced.

The potential of PM to return patients' soft tissues to normal sensation and to avoid self-inflicted STI, are highly desirable in the pediatric community and would be perceived as advantageous by many pediatric patients and their parents and/or guardians. The results revealed in our study establish an admirable clinical value for PM in means of reducing the severity of post-operative STI and in accelerating recovery time to normal function from STA in pediatric patients after dental procedures. However, the present-day cost per cartridge is somewhat high, and some dentists would be disinclined to pass the extra cost on to the patient. Moreover, given the requirement for a second injection, it is anticipated that the acceptance of PM in the pediatric population will be questioned.

The major limitation in this study is that it only included healthy children who were 5 to 8 years of age. Future research would ideally involve children younger than 5 years and special needs patients. Also blinding of the examiner/investigator might be more favorable.

\section{CONCLUSION}

Phentolamine mesylate was more effective in reducing selfinflicted soft tissue ulcers, however, other forms of injury i.e. redness, swelling, hematoma were not meaningfully reduced. PM significantly accelerated the time of return to normal function after inferior nerve block anesthesia in children.

\section{CONFLICT OF INTEREST}

The authors declared that they have no conflict of interest.

\section{REFERENCES}

1. Malamed SF. Local anesthetics: Dentistry's most important drugs, clinical update 2006. J Calif Dent Assoc. 2006;34:971-6.

2. Malamed SF. Handbook of local anesthesia-e-book. $7^{\text {th }}$ ed. London: Elsevier Health Sciences; 2019. p 1-443.

3. Malamed SF. Local anesthesia. J Calif Dent Assoc.1998;26:657, 660.
4. American Dental Association (ADA). 2002 Survey of Dental Practice-Characteristics of Dentists in Private Practice and Their Patients. American Dental Association (ADA); Chicago, IL. 2004.

5. Hersh EV, Moore PA, Saraghi M. Phentolamine mesylate: pharmacology, efficacy, and safety. Gen Dent. 2019;67:12-7.

6. College C, Feigal R, Wandera A, Strange M. Bilateral versus unilateral mandibular block anesthesia in a pediatric population. Pediatr Dent. 2000;22:453-7.

7. Staman NM, Townsend JA, Hagan JL. Observational study: discomfort following dental procedures for children. Pediatr Dent. 2013;35:52-4.

8. Katyal V. The efficacy and safety of articaine versus lignocaine in dental treatments: a meta-analysis. J Dent. 2010;38:307-17.

9. Yapp KE, Hopcraft MS, Parashos P. Articaine: a review of the literature. Br Dent J. 2011;210:323-9.

10. Moore PA, Hersh EV, Papas AS, Goodson JM, Yagiela JA, Rutherford B, et al. Pharmacokinetics of lidocaine with epinephrine following local anesthesia reversal with phentolamine mesylate. Anesth Prog. 2008;55:40-8.

11. Leimdorfer A. Prevention and abolition of cardiac arrhythmias by regitine (C-7337). Am J Physiol. 1952; 171:742-3. Quoted from: Malamed SF. Reversing local anesthesia. Inside Dentistry. 2008;4:2-3.

12. McNeil C, Copeland J. Accidental digital epinephrine injection: to treat or not to treat? Can Fam Physician. 2014;60:726-8.

13.Zentgraf M, Ludwig G, Ziegler $M$. How safe is the treatment of impotence with intracavernous autoinjection? Eur Urol. 1989;16:165-71.

14. Goswami A, Bora A, Kundu GK, Ghosh S. Reversal of Residual Soft-Tissue Anesthesia : 2014;2:86-9.

15. FDA approves OraVerse for pediatric dental patients 3 years and older. 2016. Available at: https://www.fda.gov/files/drugs/published/N22-159S011Phentolamine-mesylate-Clinical-PREA.pdf. Accessed November 27, 2019.

16. Hersh EV, Lindemeyer R, Berg JH, Casamassimo PS, Chin J, Marberger A, et al. Phase four, randomized, doubleblinded, controlled trial of phentolamine mesylate in twoto five-year-old dental patients. Pediatr Dent. 2017;39:3945.

17. Vinnakota DN, Kamatham R. Safety profile of phentolamine mesylate as reversal agent of pulpal and soft tissue dental anesthesia: a systematic review and metaanalysis. Quintessence Int. 2019;50:568-75.

18. Schulz KF, Altman DG, Moher D. CONSORT 2010 statement: Updated guidelines for reporting parallel group randomized trials. Ann Intern Med. 2010;152:726-32.

19. Tavares M, Goodson JM, Studen-Pavlovich D, Yagiela JA, Navalta LA, Rogy S, et al. Reversal of soft-tissue local anesthesia with phentolamine mesylate in pediatric patients. J Am Dent Assoc. 2008;139:1095-104. 
20. Hozo SP, Djulbegovic B, Hozo I. Estimating the mean and variance from the median, range, and the size of a sample. BMC Med Res Methodol. 2005;13:1-10.

21. Killeen PR. An Alternative to Null-Hypothesis Significance Tests. Psychol Sci. 2005;16:345-53.

22. Daniel W. Biostatistics. A foundation for analysis in the health science. $9^{\text {th }}$ ed. Chichester: Wiley; 2008. p.2-699.

23. Pannucci CJ, Wilkins EG. Identifying and Avoiding Bias in Research. Plast Reconstr Surg. 2010;126:619-25.

24. Faul F, Erdfelder E, Lang AG, Buchner A. G*Power 3: a flexible statistical power analysis program for the social, behavioral, and biomedical sciences. Behav Res Methods. 2007;39:175-91.

25. Doyle DJ, Garmon EH. American Society of Anesthesiologists classification (ASA class). StatPearls Publishing; 2019.

26. Frankl SN. Should the parent remain with the child in the dental operatory? J Dent Child. 1962;29:150-63.

27. Kim J, Shin W. How to do random allocation (randomization). Clin Orthop Surg. 2014;6:103-9.

28. Nourbakhsh N, Shirani F, Babaei M. Effect of phentolamine mesylate on duration of soft tissue local anesthesia in children. J Res Pharm Pr. 2012;1:55-9.

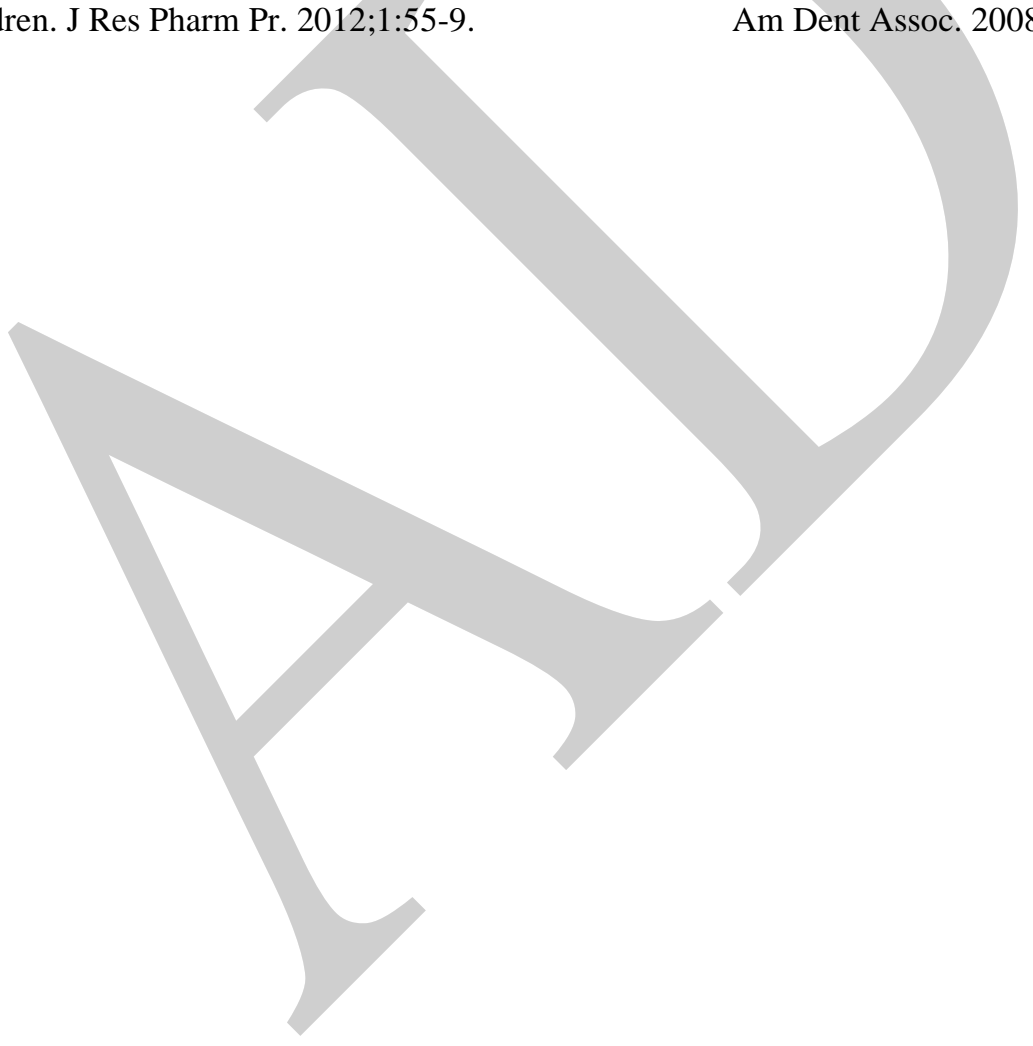

29. Fisher HB, Logemann JA. The Fisher-Logemann test of articulation competence. Boston, Houghton Mifflin; 1971. Quoted from: Hersh EV, Moore PA, Papas AS, Goodson JM, Navalta LA, Rogy S, et al. Reversal of soft-tissue local anesthesia with phentolamine mesylate in adolescents and adults. J Am Dent Assoc. 2008;139:1080-93.

30. DePippo KL, Holas MA, Reding MJ. Validation of the 3oz water swallow test for aspiration following stroke. Arch Neurol. 1992;49:1259-61.

31. Schulz KF. Subverting randomization in controlled trials. JAMA. 1995;274:1456-8.

32. Septodont Inc. OraVerse (Phentolamine Mesylate) Drug Package Insert. Available at: https://www.accessdata.fda.gov/drugsatfda_docs/label/201 6/022159s011lbl.pdf. Accessed November 27, 2019.

33. Boynes SG, Riley AE, Milbee S, Bastin MR, Price ME, Ladson A. Evaluating complications of local anesthesia administration and reversal with phentolamine mesylate in a portable pediatric dental clinic. Gen Dent. 2013;61:70-6.

34. Hersh EV, Moore PA, Papas AS, Goodson JM, Navalta LA, Rogy S, et al. Reversal of soft-tissue local anesthesia with phentolamine mesylate in adolescents and adults. J Am Dent Assoc. 2008;139:1080-93. 